\title{
MASCULINISING OVARIAN STEROID CELL TUMOR IN A 51 YEAR OLD INDIAN FEMALE: A CASE REPORT
}

\author{
Gurukiran C.S ${ }^{1}$, Pavan B.M², Fahad Tauheed ${ }^{3}$, Naveen Kumar $M^{4}$
}

\section{HOW TO CITE THIS ARTICLE:}

Gurukiran C.S, Pavan B.M, Fahad Tauheed, Naveen Kumar M. "Masculinizing ovarian steroid cell tumor in a 51 year old Indian female: a case report". Journal of Evolution of Medical and Dental Sciences 2013; Vol2, Issue 33, August 19; Page: 6241-6246.

\begin{abstract}
Virilizing or masculinizing features in a female can be an alarm for the doctor and a source of embarrassment for the patient. These features appear as a result of hyperandrogenism, the source being ovary or adrenal gland. Here is a case of Virilizing ovarian tumour in a 51 year old diabetic female. This patient presented with a 14 year history of appearance of hair all over the body with loss of scalp hair. She also had complaints of pain in lower abdomen with excessive micturition for 3 months. Examination showed hirsutism and features of virilisation. Suprapubic mass was present on abdominal examination. Per vaginal exam revealed a soft mass? Ovarian. Radiological tests showed features suggestive of ovarian malignancy with possible uterine involvement and mild ascites. Most routine hematological investigations were normal. Total testosterone was grossly elevated $(>1500 \mathrm{ng} / \mathrm{dl})$; CA-125 was also raised $(103.7 \mathrm{U} / \mathrm{ml})$. FSH \& $\mathrm{LH}$ values were low, TSH was normal while estradiol\& progesterone were raised. Urine microscopy had features of urinary tract infection; hence treatment was started for the same. Patient underwent panhysterectomy. Histopathological studies confirmed steroid cell left ovarian tumour (T1aN0Mx), which was the source of virility in the patient. Patient improved dramatically after the surgery with reversal of androgenic features (partial).key words: steroid cell tumor, hirsutism, and panhysterectomy.
\end{abstract}

INTRODUCTION: Steroid cell tumors are tumors composed entirely or predominantly of cells resembling steroid hormone secreting cells. They are classified under sex cord-stromal tumors which account for approximately $8 \%$ of all ovarian tumors. These tumours can be a source of testosterone and other steroids, hence can cause hirsutism and virilisation in a female adults and precocious puberty in children. ${ }^{1-4}$

Approximately one-third of the steroid cell tumours have been reported to be malignant. ${ }^{1}$

Since Virilizing tumours of the ovary account for only $0.1 \%$ of all ovarian tumours, not much has been studied on the modalities of treatment for the same. Although surgery has been the mainstay, a recent report showed that gonadotropin releasing hormone agonist was effective in treating steroid cell tumors. ${ }^{5-6}$

Here, we present a case of a 51year old lady who presented with hirsutism, virilisation of 14 year duration and was found to have steroid cell tumour of the left ovary measuring $12 \times 12 \times 9$ $\mathrm{cm}$. She showed drastic reversal of symptoms following panhysterectomy and was declared free of tumour.

CASE PRESENTATION: A 51 year old primary school teacher presented to the surgical OPD with signs and symptoms of hirsutism and virilisation- male pattern of baldness, unwanted hair growth all over the body including beard and moustache, regression of breasts, etc. of 14 years duration (since 1998). She had additional complaints of pain in the lower abdomen with excessive micturition for past 2 months. Her obstetric score was Para-2 Living-2. Both deliveries were full term vaginal and uneventful and the children are alive and healthy. Last child birth was 
28 years back and she has been amenorrheic since 1998. She was a known case of Diabetes Mellitus for 5 years- on glibenclamide. She was not on any other medication. There was no history suggestive of hypothyroidism or hyperprolactinemia. Family history was unremarkable.

On examination, the patient was moderately built and nourished, conscious and cooperative, with no pallor, icterus, oedema or lymphadenopathy. BMI was $23 \mathrm{~kg} / \mathrm{m}^{2}$, pulse 84 beats per minute, blood pressure $130 / 80 \mathrm{~mm}$ of $\mathrm{Hg}$, and respiratory rate 20cycles/minute. Patient was afebrile.

Systemic examination revealed no cardio-respiratory abnormalities. Per abdomen showed supra-pubic mass.

Investigations-She had a fasting and post prandial blood sugar levels of 120 and 218 $\mathrm{mg} / \mathrm{dl}$ respectively (both rose); blood urea (16 $\mathrm{mg} \%$ ), serum creatinine (0.7 $\mathrm{mg} \%$ ), chest x-ray, ECG and CBC were found to be normal. Testosterone levels were found to be elevated $(>1500$ $\mathrm{ng} / \mathrm{dl})$ and so was CA-125 (103.7 U/ml). Follicle stimulating hormone $(0.39 \mathrm{mIU} / \mathrm{ml})$ and Luteinizing hormone $(0.01 \mathrm{mIU} / \mathrm{ml})$ were found to be abnormally low and oestrogen $(191.84$ $\mathrm{pg} / \mathrm{ml})$ was abnormally high. Thyroid stimulating hormone $(0.96 \mu \mathrm{IU} / \mathrm{ml}$ was normal.

Ultrasonography of abdomen revealed an irregular complex mass lesion of $15 \times 10 \mathrm{~cm}$ in pelvis (predominantly solid with few cystic areas).Doppler evaluation showed extensive neovascularity. Ovaries were not made out separately. Mild ascites was present. Uterus was bulky showing an anterior myometrial mass of $4.3 \mathrm{~cm}$ size. Overall picture of USG was suggestive of ovarian malignancy with peritoneal spread, with the mass in uterus possibly due to uterine involvement.

Computed tomography: Complex mass measuring $18.5 \times 12.5 \times 13.5 \mathrm{~cm}$ with both solid \& cystic component in the pelvis more towards left side; bulky uterus with heterogeneous attenuation value; mild ascites more limited pelvis (Features suggestive of ovarian malignancy).

Pan hysterectomy was done after taking consent. Peri-operative period was uneventful. Patient showed drastic regression of masculinizing features and returned back to near normalcy.

Histopathology reports suggested steroid cell tumour-ovary. Gross features: Size 12x12x9 $\mathrm{cm}$, external surface-multiple bosselation, no breach in capsule. Cut section- multiple bright yellow nodular lesions and 3 cystic spaces filled with gelatinous material, few grey white $(8 \times 3.5 \mathrm{~cm})$ discolorations.

Microscopy: neoplastic cells in sheets separated by delicate fibrous septae, polygonal with hyperchromatic round nuclei and eosinophilic to clear abundant cytoplasm; capsule free from invasion; lymph nodes show reactive changes with sinus histiocytosis (T1aN0Mx).

DISCUSSION: Ovarian tumours are pathologically diverse. They are classified on the basis of their origin into four broad categories- surface epithelial-stromal cell tumours, germ cell tumours, sex cord stromal tumours, and metastasis to ovaries. Steroid cell tumours are sex cord stromal tumours.

- $\quad$ Steroid cell tumors

Stromal luteoma

Leydig cell tumor group

- Hilus cell tumor

- Leydig cell tumors nonhilar type

- Leydig cell tumors, not otherwise specified steroid cell tumors, not otherwise specified (NOS)

- Well differentiated

- Malignant 
Stromal luteoma are defined as small steroid cell tumors that are confined to the ovarian stroma and do not have crystals of Reinke. Reinke crystals are slender rods with square or tapered ends, within an incomplete "halo," and best seen when stained bright red with Mallory trichrome stain. Stromal luteoma usually occurs in postmenopausal women and is associated with estrogenic effects commonly in the form of abnormal vaginal bleeding. Rarely, androgenic manifestations may be present.

Leydig cell tumors are rare ovarian steroid cell neoplasms composed of Leydig cell that contain Reinke crystals. Depending on their location, they are divided into hilus cell tumors and Leydig cell tumors of non hilar type. A hilus cell tumor is a Leydig cell tumor of the ovary that arises in the ovarian hilus. Leydig cell tumor, hilar cell type, are unilateral, small, mostly microscopic, yellow-to-brown, soft, fleshy, circumscribed masses in the hilar region of the ovary and adjacent mesovarium. Leydig cell tumors are composed of closely packed sheets or solid cords of uniform, polyhedral, and eosinophilic cells. Nuclei are round, central, and vary in size. They frequently give an appearance of being unevenly distributed in the tumor with "nuclearrich" and "nuclear-poor" zones, a feature regarded as almost pathognomonic of Leydig cell differentiation, even in the absence of Reinke crystals. Mitoses are rare. Leydig cell cytoplasm is densely eosinophilic and finely granular with small lipid-containing cytoplasmic vacuoles. PASpositive yellow brown lipochrome pigment is seen in many cells. Leydig cell tumor, non hilar type, is composed of steroid cells containing Reinke crystals and surrounded by ovarian stroma that often shows stromal hyperthecosis, and except for their location, the clinical and pathological features of the non hilar type is similar to that of the hilar type.

Steroid cell tumors, NOS occur most often in women of reproductive age, particularly during the third and fourth decades, and rarely in postmenopausal women or children. They are clinically androgenic in $40 \%$ of cases and regularly secrete androstenedione, $\alpha$ hydroxyprogesterone, and testosterone. About $30 \%$ of cases are clinically malignant and have an extra ovarian spread of tumor at the time of operation.

The noticeable presentation of a patient with a Virilizing ovarian tumour is hirsutism and virilisation because of hyperandrogenism, as seen in this case. Other symptoms include abdominal pain, abdominal distention, and bloating.

Virilisation is a two phased process: first, there is defeminization like development of oligomenorrhea or amenorrhea, regression of the breasts and external genitalia, atrophy of the uterus and adnexa, and loss of the female body contour; second, there is masculinization which includes hirsutism, acne, clitoral enlargement, increased libido, sterility, enlargement of the larynx, deepening of the voice, increased muscle mass and temporal alopecia.

Other abnormalities associated with excessive levels of androgen are cardiovascular disease, dyslipidemia, glucose intolerance/insulin resistance and hypertension. Acanthosis nigricans, a marker for insulin resistance, may also be present. This patient was a known diabetic.

A high total testosterone concentration indicates that hyperandrogenaemia may be caused by an ovarian or adrenal tumour. If the total testosterone is normal or only slightly raised, an androgen-secreting tumour can be excluded. Testosterone concentrations more than 1.5-2 times the upper limit of normal or a history of rapid virilisation are likely to be associated with tumour-associated hyperandrogenism. Dehydroepiandrosterone sulphate and androstenedione should then be measured to identify an adrenal or ovarian source of the hyperandrogenaemia (not done in this case because of direct evidence of ovarian mass).

On radiological imaging, virilizing steroid cell tumors of the ovary are usually one sided and often small, only slightly bigger than the normal ovary, usually confined to the ovary at presentation, predominantly solid or mostly solid, non-calcified, and not associated with ascites. 
Small steroid cell tumors have been described as slightly hypoechoic or hyperechoic (compared to the ovary) with high diastolic flow on doppler interrogation. They may be difficult to identify on radiological imaging, in part because they are isoechoic to the uterus on ultrasound and iso attenuating on CT. MRI can help detect small tumours.

Histopathological examination confirms the diagnosis as seen in this case, where we came to a conclusion that this was a case of well differentiated steroid cell tumour (NOS).

Treatment options have not been explored much due to the rarity of the disease. Early detection has good surgical outcomes. Surgery remains the mainstay of treatment. Total abdominal hysterectomy, bilateral salpingo-oophorectomy, and complete surgical staging are an appropriate management option for old women who do not want to preserve their fertility. ${ }^{7}$ In young patients, unilateral salpingo-oophorectomy is sufficient due to the low bilateral frequency of $6 \%$.However, a mandatory follow-up evaluation of sex hormone measurement is a must in such cases. $^{7}$

\section{REFERENCES:}

1. Scully RE. Atlas of Tumor Pathology. 2nd ed. Washington, DC: Armed Forces Institute of Pathology; 1979. Tumors of the ovary and maldeveloped gonads, fallopian tube, and broad ligament; pp. 215-220.

2. Hayes MC, Scully RE. Ovarian steroid cell tumors (not otherwise specified) Am J Surg Pathol.1987; 11:835-845. [PubMed]

3. Hartman LC, Young RH, Evans MP, Podratz KC. Ovarian sex cord-stromal tumors. In: Hoskins WJ, Perez CA, Young RC, editors. Principles and Practice of Gynecologic Oncology. 2nd ed. Philadelphia: Lippincott-Raven; 1997. pp. 1015-1019.

4. Wang PH, Chao HT, Lee RC, Lai CR, Lee WL, Kwok CF, et al. Steroid cell tumors of the ovary: clinical, ultrasonic, and MRI diagnosis--a case report. Eur J Radiol. 1998; 26:269273. [PubMed]

5. Brewer CA, Shevlin D. Encouraging response of an advanced steroid-cell tumor to GnRH agonist therapy. Obstet Gynecol. 1998; 92(4 Pt 2):661-663. [PubMed]

6. Wang PH, Chao HT, Lee WL. Use of a long-acting gonadotropin-releasing hormone agonist for treatment of steroid cell tumors of the ovary. FertilSteril. 1998; 69:353- 355. [PubMed])

7. Young Tae Kim, Sang WunKim, Bo Sung Yoon, Sung Hoon Kim, Jae Hoon Kim, Jae Wook Kim, and Nam Hoon Cho An Ovarian Steroid Cell Tumor Causing Virilization and Massive Ascites. Yonsei Med J. 2007 February 28; 48(1): 142-146. 
PICTURE 1: PATIENT WITH ANDROGENIC FEATURES
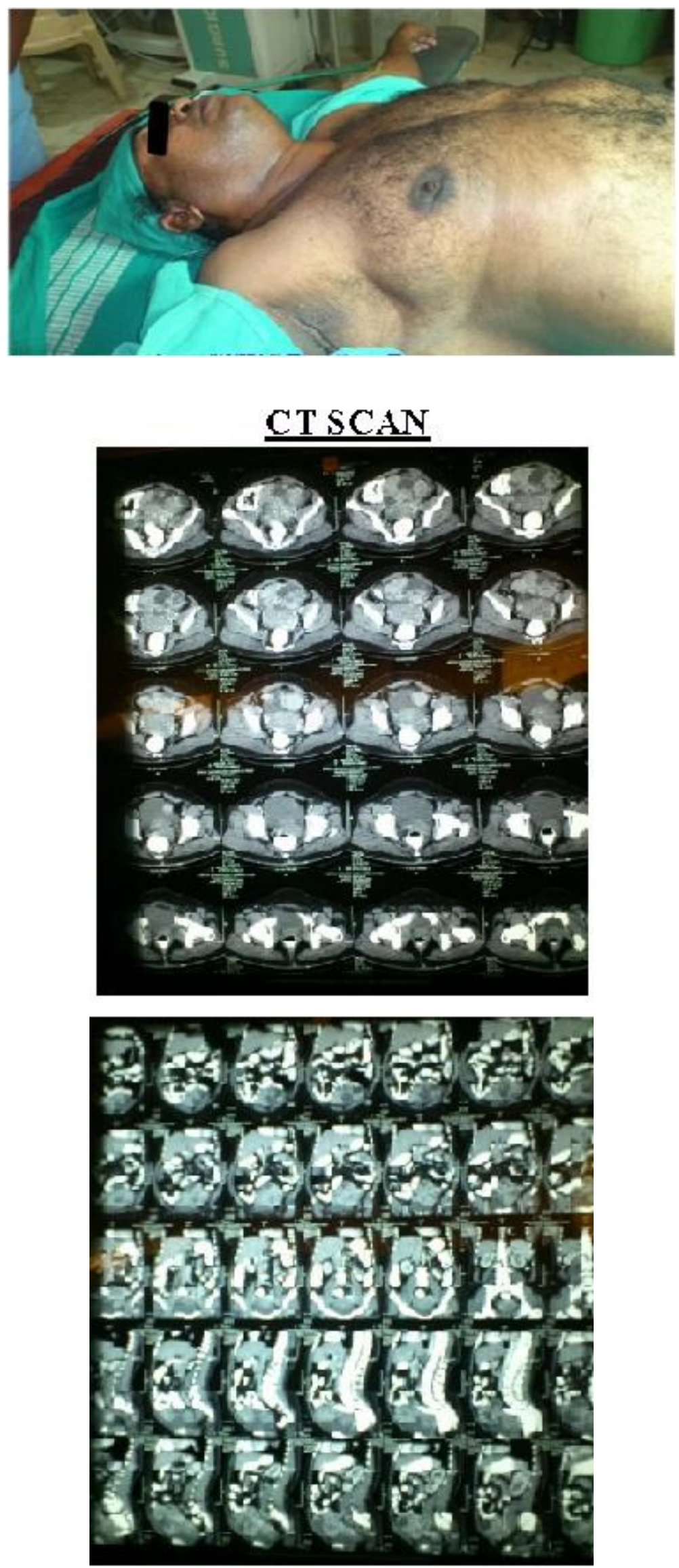


\section{CASE REPORT}

\section{PICTURE 3: INTRAOPERATIVE PICTURE SHOWING THE TUMOR}

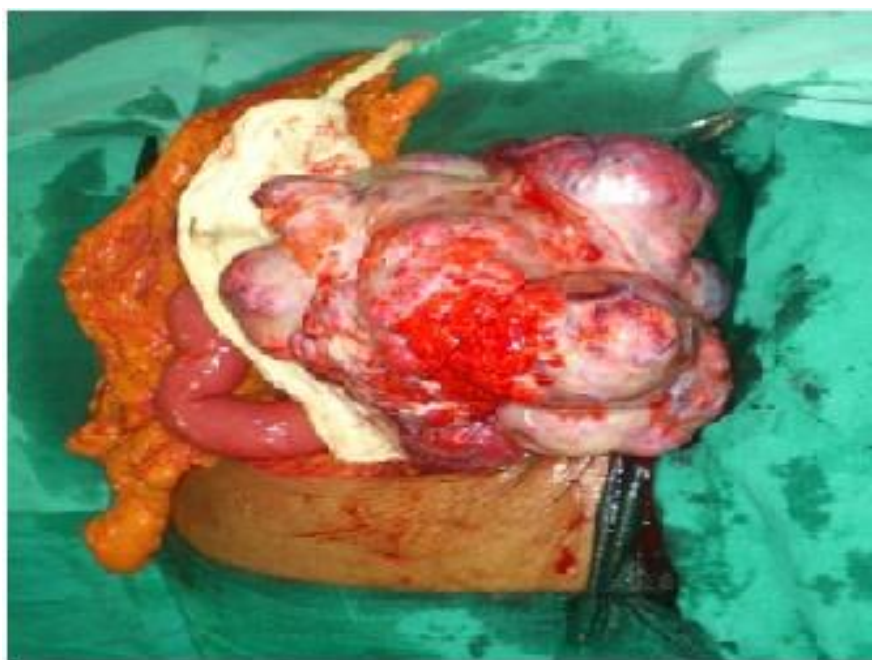

\section{AUTHORS:}

1. Gurukiran C.S.

2. Pavan B.M.

3. Fahad Tauheed

4. Naveen Kumar M.

\section{PARTICULARS OF CONTRIBUTORS:}

1. Associate Professor, Department of General Surgery, Sree Siddartha Medical College \& Research Hospital, Tumkur.

2. Assistant Professor, Department of General Surgery, Sree Siddartha Medical College \& Research Hospital, Tumkur.

3. Senior Resident, Department of General Surgery, Sree Siddartha Medical College \& Research Hospital, Tumkur.
4. Assistant Professor, Department of General Surgery, Sree Siddartha Medical College \& Research Hospital, Tumkur.

\section{NAME ADRRESS EMAIL ID OF THE CORRESPONDING AUTHOR:}

Dr. Gurukiran C.S.

Associate Professor,

Department of Surgery, SSMC,

Agalakote, Tumkur - 7

Email-csgurukiran@gmail.com

Date of Submission: 18/06/2013.

Date of Peer Review: 20/07/2013.

Date of Acceptance: 27/07/2013.

Date of Publishing: 14/08/2013 